Article

\title{
Characterization of Defined Pt Particles Prepared by Ultrasonic Spray Pyrolysis for One-Step Synthesis of Supported ORR Composite Catalysts
}

\author{
${\text { Gözde Alkan }{ }^{1} \text {, Milica Košević }}^{2, *(\mathbb{D})}$, Marija Mihailović ${ }^{2} \mathbb{D}$, Srecko Stopic $^{3}$, Bernd Friedrich ${ }^{3} \mathbb{D}$, \\ Jasmina Stevanović ${ }^{2,4}$ and Vladimir Panić ${ }^{2,4,5}$ (D)
}

Citation: Alkan, G.; Košević, M.; Mihailović, M.; Stopic, S.; Friedrich,

B.; Stevanović, J.; Panić, V.

Characterization of Defined Pt Particles Prepared by Ultrasonic Spray Pyrolysis for One-Step Synthesis of Supported ORR Composite Catalysts. Metals 2022, 12, 290. https://doi.org/10.3390/ met12020290

Academic Editors: Laichang Zhang and Thomas Gries

Received: 26 December 2021

Accepted: 2 February 2022

Published: 8 February 2022

Publisher's Note: MDPI stays neutral with regard to jurisdictional claims in published maps and institutional affiliations.

Copyright: (C) 2022 by the authors. Licensee MDPI, Basel, Switzerland. This article is an open access article distributed under the terms and conditions of the Creative Commons Attribution (CC BY) license (https:// creativecommons.org/licenses/by/ $4.0 /$ )
1 Deutsches Zentrum für Luft- und Raumfahrt (DLR), Linder Höhe 1, 51147 Cologne, Germany; goezde.alkan@dlr.de

2 Institute of Chemistry, Technology and Metallurgy, University of Belgrade, Njegoševa 12 11000 Belgrade, Serbia; marija.mihailovic@ihtm.bg.ac.rs (M.M.); j.stevanovic@ihtm.bg.ac.rs (J.S.); panic@ihtm.bg.ac.rs (V.P.)

3 IME Process Metallurgy and Metal Recycling, RWTH Aachen University, 52056 Aachen, Germany; sstopic@ime-aachen.de (S.S.); bfriedrich@ime-aachen.de (B.F.)

4 Centre of Excellence in Environmental Chemistry and Engineering-ICTM, University of Belgrade, 11000 Belgrade, Serbia

5 Chemical-Technological Department, State University of Novi Pazar, 36300 Novi Pazar, Serbia

* Correspondence: milica.kosevic@ihtm.bg.ac.rs; Tel.: +3811-136-40231

\begin{abstract}
Polygonal Pt nanoparticles were synthesized using ultrasonic spray pyrolysis (USP) at different precursor concentrations. Physicochemical analysis of the synthesized Pt particles involved thermogravimetric, microscopic, electron diffractive, and light absorptive/refractive characteristics. Electrochemical properties and activity in the oxygen reduction reaction (ORR) of the prepared material were compared to commercial Pt black. Registered electrochemical behavior is correlated to the structural properties of synthesized powders by impedance characteristics in ORR. The reported results confirmed that $\mathrm{Pt}$ nanoparticles of a characteristic and uniform size and shape, suitable for incorporation on the surfaces of interactive hosts as catalyst supports, were synthesized. It is found that USP-synthesized Pt involves larger particles than Pt black, with the size being slightly dependent on precursor concentration. Among ORR-active planes, the least active (111) structurally defined the synthesized particles. These two morphological and structural characteristics caused the USP-Pt to be made of lower Pt-intrinsic capacitive and redox currents, as well as of lower ORR activity. Although being of lower activity, USP-Pt is less sensitive to the rate of ORR current perturbations at higher overpotentials. This issue is assigned to less-compact catalyst layers and uniform particle size distribution, and consequently, of activity throughout the catalyst layer with respect to Pt black. These features are considered to positively affect catalyst stability and thus promote USP synthesis for improved properties of host-supported Pt catalysts.
\end{abstract}

Keywords: electrocatalysis; nanocatalyst; noble metal nanoparticles

\section{Introduction}

There are numerous contemporary studies dealing with the catalytic improvements of energetics-important electrochemical processes such as hydrogen evolution (HER) and the reduction and oxidation of oxygen or small organic molecules [1]. Particularly, investigations into oxygen reduction reaction (ORR) kinetics are of the highest interest due to the ORR rate-determining characteristics for energy conversion in fuel cells (FCs) and metal-air batteries $\left(\mathrm{M}-\mathrm{O}_{2}\right)$ [2-5]. The meeting point of $\mathrm{FCs}$ and $\mathrm{M}-\mathrm{O}_{2}$ (involving alkaline metal-air batteries, such as $\mathrm{Li}-\mathrm{O}_{2}$ and $\mathrm{Na}-\mathrm{O}_{2}$ ) clearly exists on the cathode side - in both FC and $\mathrm{M}-\mathrm{O}_{2}$, the electrons for anodic oxidations are provided by ORR at the cathode [6]. Green technology progress not just in energy storage but in the water-splitting domain urges 
for controllable catalysts for both HER and OER $[7,8]$. New modifications of morphology and/or electronic structures of transition metal-based catalysts have offered multifunctional solutions in energy storage and conversion as well as in demanded water electrolysis applications [9]. Among various electrode materials and catalysts, such as nanostructured metals, metal oxides, hydroxides, phosphides, and chalcogenides, Pt-based catalysts are still at the forefront owing to their high activity with acceptable stability and slow chemical degradation $[10,11]$.

Besides material selection, surface properties, such as the structure, size, and shape of the nanoparticles, also have a great impact, especially on rather sluggish ORR activity, due to the intrinsic sensitivity of this complex heterogeneous reaction regarding the catalyst surface. Therefore, the synthesis method considerably affects the catalyst ORR activity. The examination of various synthesis methods for Pt nanoparticles (Pt NPs) themselves as well as various Pt-based composites has also been the focus of much research. Chemical precipitation, ion implantation, laser ablation, and chemical reduction have been the most investigated methods so far [12]. In most of the studies, additives were used to control the shape of the fine Pt NPs, such as etchants, adsorbates, surfactants, polymers, or foreign metal ions $[4,13,14]$. However, the simple synthesis of fine spherical Pt NPs without any additive is rare, especially in bottom-up approaches. Recently, the pulsed laser ablation method in liquids (PLAL) has been utilized by Lau et al. [15]. The successful synthesis of ligand-free pure Pt NPs was achieved and it was reported that possible toxic cross-effects and additional nanoparticle purification steps such as filtration, dialysis, and centrifugation were avoided.

Among various bottom-up approaches, ultrasonic spray pyrolysis (USP) was reported as the one that easily enables the generation of ultrafine, uniform or complex structures with controlled stoichiometry as well as chemical and phase content [16-19], which could be very promising for the synthesis of $\mathrm{Pt}$ nanocatalyst with good ORR activity $[20,21]$. There are a few studies dealing with Pt-based catalyst synthesis by USP, especially in hybrid form with metal oxides such as $\mathrm{SiO}_{2}, \mathrm{CeO}_{2}, \mathrm{Al}_{2} \mathrm{O}_{3}$, and $\mathrm{FeAl}_{2} \mathrm{O}_{4}$ [22,23], and also with $\mathrm{Pt} / \mathrm{TiO}_{2}$, as carried out by Košević et al. [24], which is of great concern as an interactive Pt support. In these studies, the catalysts synthesized through USP were reported to exhibit superior catalytic activity with respect to wet chemical, colloidal, and dry impregnation methods [25-28]. However, there is a lack of systematic studies dealing with the synthesis of pure nanoparticles through controlled USP.

Therefore, we aimed to synthesize Pt NPs by a precursor solution concentrationdependent USP process and analyze its influence on morphological, structural, and electrochemical properties of Pt NPs. The ORR activity of Pt NPs synthesized exclusively by USP was elucidated and compared to commercial Pt powder to reveal the potential of the further use of USP in the synthesis of complex Pt-based electrocatalysts. In this way, USP was introduced as a novel approach for the simple synthesis of Pt NPs, whose structural and morphological characteristics can be finely tuned via easily-controllable pyrolytic parameters such as precursor concentration and temperature.

\section{Materials and Methods}

\subsection{Material Synthesis}

$\mathrm{H}_{2} \mathrm{PtCl}_{6} \mathrm{H}_{2} \mathrm{O}$ (Sigma Aldrich) was used as Pt precursor. In total, $2 \mathrm{~g}$ or $4 \mathrm{~g}$ of $\mathrm{H}_{2} \mathrm{PtCl}_{6}$ $6 \mathrm{H}_{2} \mathrm{O}$ was dissolved in $1 \mathrm{~L}$ of de-ionized water to obtain the USP-feeding solutions. Twozones ultrasonic spray pyrolysis was utilized for the formation of Pt nanoparticles, whose details can be found elsewhere [10,17]. In the first heating zone, droplets experience evaporation, while in the second heating zone and with the addition of hydrogen, the material reduction into Pt NPs takes place. The precursor solution was atomized by an ultrasonic generator $(1.7 \mathrm{MHz})$ with fine droplets subsequently transported into the heating zones to experience evaporation, thermal reduction, and precipitation into Pt metallic nanoparticles. As carrier and reaction gases, $1.5 \mathrm{~L} / \mathrm{min} \mathrm{N}_{2}$ in the first heating zone and 
$1.5 \mathrm{~L} / \min \mathrm{N}_{2}+0.5 \mathrm{~L} / \operatorname{min~}_{2}$ in the second heating zone were utilized. The residence time was estimated as $t_{\text {residence }}=\frac{V_{\mathrm{r}} \cdot T_{\text {room }}}{r_{F} \cdot T_{r}}$, which provides the value of $3.01 \mathrm{~s}$.

\subsection{Material Characterization}

\subsubsection{Composition, Morphology, and Structural Characterization}

To reveal the effect of precursor solution concentration on morphology, size, and purity of Pt nanoparticles, two different concentrations were examined. UV-Vis (Agilent, Santa Clara, CA 95051, USA) and DLS measurements (Malvern Panalytical Ltd, Kassel, Germany), scanning transmission electron microscopy (STEM), and thermal gravimetric analysis (TGA, NETZSCH, Selb, Germany) analyses were performed with typical instrumentations and conditions. The morphology and elemental compositions of the synthesized powders were analyzed by STEM Tecnai F20 (FEI Company, Eindhoven, The Netherlands), and a system (EDAX Inc., Mahwah, NJ, USA) equipped with energy dispersive spectroscopy (EDX) operated at $200 \mathrm{KV}$ for the analysis of characteristic X-ray emissions.

\subsubsection{Electrochemical Characterization}

Electrochemical characterization of the prepared Pt NPs was performed by linear sweep polarization measurements (LSV) and galvanostatic electrochemical impedance spectroscopy (GEIS) during the oxygen reduction reaction (ORR) as well as by cyclic voltammetry (CV). LSV and CV were conducted at sweep rates of 1 and $50 \mathrm{mV} \mathrm{s}^{-1}$, respectively; LSV and GEIS measurements were performed at a working electrode (WE) rotation speed of $1500 \mathrm{rpm}$. In total, $0.5 \mathrm{M} \mathrm{H}_{2} \mathrm{SO}_{4}$ purged with $\mathrm{N}_{2}(\mathrm{CV})$ or $\mathrm{O}_{2}(\mathrm{ORR}$ and GEIS) was used as an electrolyte.

It is known that $\mathrm{HSO}_{4}{ }^{-}$and $\mathrm{SO}_{4}{ }^{2-}$ are interfering anions in ORR due to their competing adsorption onto Pt active sites that are required to be occupied by oxygen adatoms [29]. If one needs to step deep into an analysis of ORR kinetics, synthetic solutions of hardly adsorbing anions, e.g., $\mathrm{HclO}_{4}$, are to be applied. However, the working environment of FC Pt-based catalysts is prone to anion adsorption from cheap and abundant solutions. Therefore, some studies deal with ORR in $\mathrm{H}_{2} \mathrm{SO}_{4}$ solution [30-32] as well. Our goal was to examine USP-Pt in such "competing adsorption" conditions and to compare the registered behavior to Pt black in the same environment.

All electrochemical measurements were performed in a three-electrode cell with an SCE reference electrode (all potentials in the paper are provided on an SCE scale) and a platinum plate as a counter electrode on potentiostat/galvanostat Bio-Logic SP200 (BioLogic SAS, Grenoble, France). WE was prepared from a powdered sample as follows: $3 \mathrm{mg}$ of the synthesized USP powder was dispersed in $1 \mathrm{~mL}$ of distilled water and ultrasonically homogenized for $1 \mathrm{~h}(40 \mathrm{kHz}, 70 \mathrm{~W})$. The obtained suspension was pipetted onto WE to form a $0.31 \mathrm{mg} \mathrm{cm}^{-2}$ Pt layer onto a glassy carbon disk electrode $\left(0.196 \mathrm{~cm}^{2}\right)$ that served as a current connector and was room-dried. Bearing in mind that the literature data [2] showed that $\mathrm{Pt}$ oxide formation could influence the structure of the $\mathrm{Pt}$ and hence its activity, CV measurements prior to LSV and GEIS measurements were conducted in the two different potential regions. Particularly, the cathodic potential was fixed at $-0.2 \mathrm{~V}$ while the anodic limit was set to 0.55 or $1.25 \mathrm{~V}$. Upon recording the stable $\mathrm{CV}$ curve in both applied potential regions, i.e., $-0.2-0.55$ without $\mathrm{Pt}$ oxide formation and $-0.2-1.25 \mathrm{~V}$ with Pt oxide formation, LSV measurement was performed that started from $0.55 \mathrm{~V}$ and from open circuit potential, $E_{\mathrm{oc}}$, respectively. GEIS was recorded down the polarization curve with a sinusoidal current of $30 \mu \mathrm{A}$ amplitude, in a single sine mode, within a frequency range of $300 \mathrm{kHz}-20 \mathrm{mHz}$, and with 20 points per decade.

Results of the electrochemical characterization were compared to those of commercial Pt black (Alfa Aesar, 25.0-29.8 $\mathrm{m}^{2} / \mathrm{g}, d: 4.68-5.58 \mathrm{~nm}$ ). 


\section{Results}

\subsection{DLS, STEM, and TGA Characterization of Pt Samples}

In order to reveal the thermal breakdown behavior of the Pt precursor, $\mathrm{H}_{2} \mathrm{PtCl}_{6} 6 \mathrm{H}_{2} \mathrm{O}$, for determining the USP reaction temperature, TGA analysis was performed in an inert atmosphere. The results are presented in Figure 1.

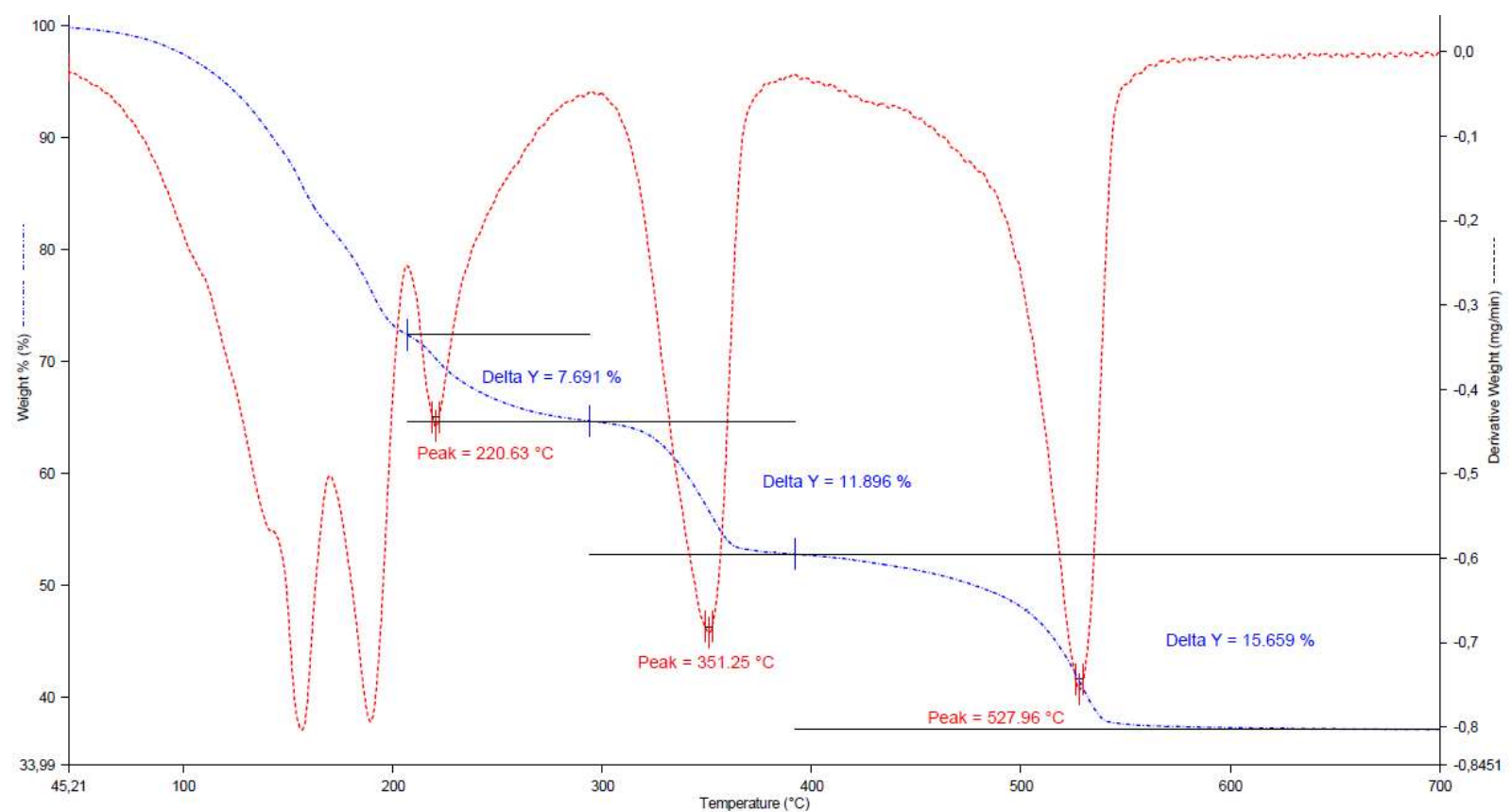

Figure 1. TGA curve of $\mathrm{H}_{2} \mathrm{PtCl}_{6} 6 \mathrm{H}_{2} \mathrm{O}$ precursor in $\mathrm{N}_{2}$.

It was previously reported by Rowston and Ottaway [16] and Schweizer and Kerr [18] that the thermal decomposition of $\mathrm{H}_{2} \mathrm{PtCl}_{6}$ takes place through stepwise reactions, as follows:

$$
\begin{gathered}
\mathrm{H}_{2} \mathrm{PtCl}_{6} \rightarrow \mathrm{PtCl}_{4}+2 \mathrm{HCl} \\
\mathrm{PtCl}_{4} \rightarrow \mathrm{PtCl}_{2}+\mathrm{Cl}_{2} \\
\mathrm{PtCl}_{2} \rightarrow \mathrm{Pt}+\mathrm{Cl}_{2}
\end{gathered}
$$

As revealed by Figure 1, mass loss began at early temperatures due to the loss of chemically bound water (the two peaks at around 170 and $190^{\circ} \mathrm{C}$ ). The mass loss related to the peak at $170{ }^{\circ} \mathrm{C}$ was below $20 \%$, which corresponds to the stoichiometric loss of five water molecules (17.4\%). The two peaks at 190 and $221^{\circ} \mathrm{C}$ can be associated with the joint loss of the remaining $6^{\text {th }}$ crystalline water molecule and two $\mathrm{HCl}$ molecules, according to Reaction (1), as the corresponding sum of mass losses of $17 \%$ was quite close to the stoichiometric $17.6 \%$. It follows that the last water molecule was lost at the temperature of $190{ }^{\circ} \mathrm{C}$ by overlapping with the start of the precursor decomposition to $\mathrm{PtCl}_{4}$, which ends up at $300{ }^{\circ} \mathrm{C}$. The loss of the remaining chlorine and the generation of metallic $\mathrm{Pt}$ through Reactions (2) and (3) is represented by the two well-separated peaks at 351 and $523{ }^{\circ} \mathrm{C}$ with an overall mass loss of $27.5 \%$, which is negligibly different from the stoichiometric $27.4 \%$. Hence, complete transformation into Pt took place at around $550{ }^{\circ} \mathrm{C}$.

In order to facilitate the reduction for shorter residence times at a slightly lower temperature of $500{ }^{\circ} \mathrm{C}$ with respect to TGA while simultaneously having a defined structure and size of Pt particles, $\mathrm{H}_{2}$ was utilized in USP synthesis.

TEM micrographs along with corresponding selected area (electron) diffraction (SAED) analysis of USP-synthesized Pt nanoparticles with different USP precursor concentrations are represented in Figure 2. 

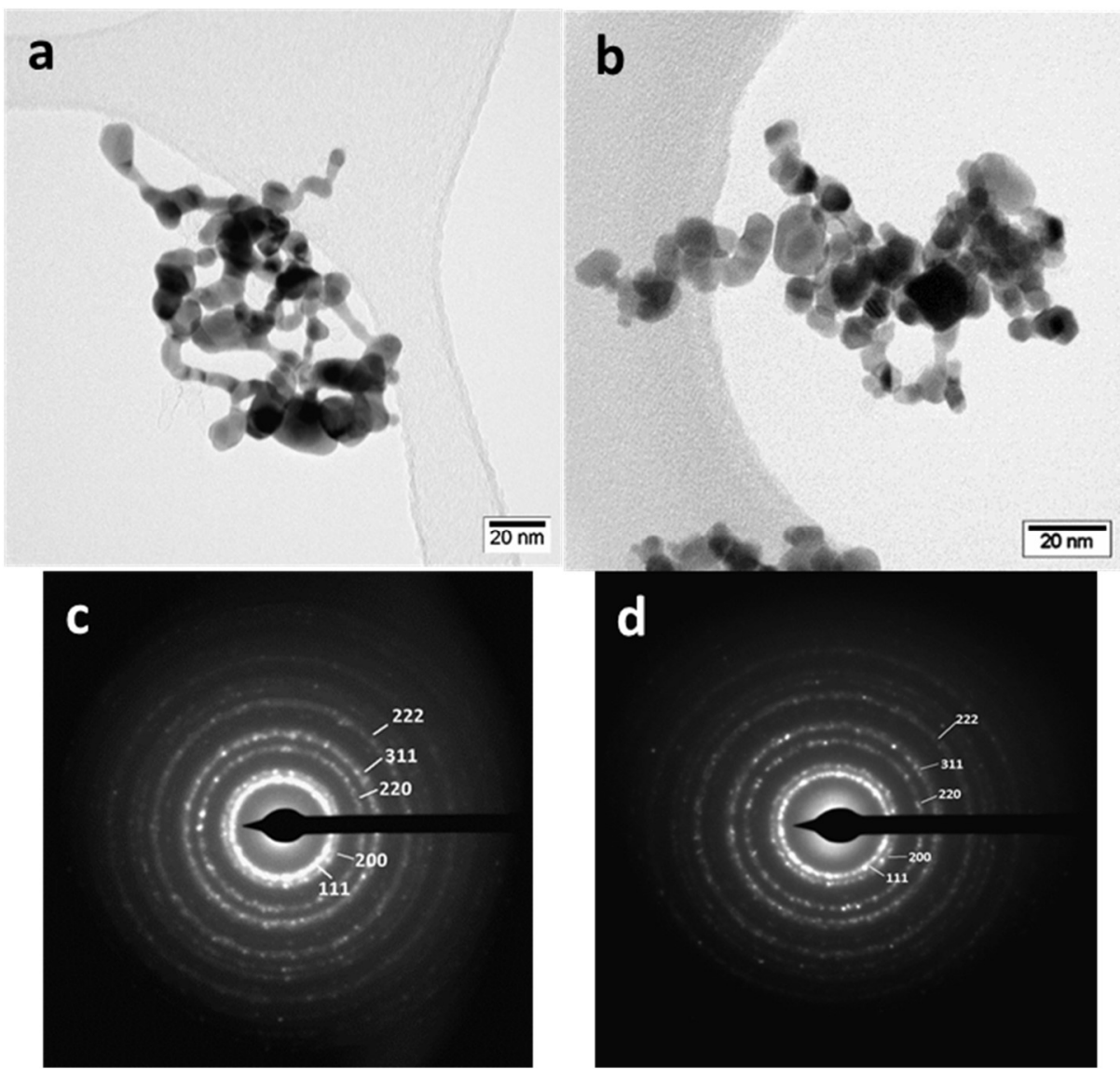

Figure 2. TEM micrographs of Pt nanoparticles synthesized by precursor concentrations of: (a) 2; (b) $4 \mathrm{~g} / \mathrm{L}$; and corresponding selected area (electron) diffraction analysis (c) and (d), respectively.

Both samples consisted of fine crystals $(5-15 \mathrm{~nm})$ with polygonal soft-edge morphology. Slightly larger and more agglomerated particles were obtained with a higher precursor concentration (Figure 2a,b). A string-like 1D agglomeration of the smallest particles appeared a more pronounced at a lower concentration. The additional effect of precursor concentration can be observed when Figure $2 \mathrm{a}, \mathrm{b}$ is analyzed. A lower concentration $(2 \mathrm{~g} / \mathrm{L})$, which can be considered as a lower driving force for particle growth, resulted in higher nucleation rates and growth of the crystals to a smaller extent, as we previously reported [17]. Consequently, the particles from the lower concentration appeared smaller and less defined and hence tended to form a string-like 1D agglomeration.

The SAED images in Figure 2c,d represent the characteristic diffraction of a ring pattern with some brighter and more distinct spots in the rings, which indicates the presence of some larger crystallites. However, the rings were still relatively continuous, which means that the crystallites were small, in the nm range, and in a random orientation. The electron diffraction spots could be described by a cubic crystal structure of Pt FCC, space group Fm $3^{-} \mathrm{m}$, with indices as shown in the pattern.

The optical properties of nanoparticles were also examined in a comparative manner by UV-Vis spectroscopy, as provided in Figure 3.

As shown in Figure 3, both observed maximum absorbance peaks appeared at $272 \mathrm{~nm}$, which is slightly higher than the absorbance values reported in the literature $(\sim 262 \mathrm{~nm})$ where Pt nanoparticles exhibited a prevailing size of 5-6 nm [20,21]. A slight red shift could be due to an aggregation effect, as revealed in the TEM micrographs shown in Figure 2. When the surface plasmon-induced absorbances of two samples are compared, it can be seen that peak position did not change and the higher concentration sample resulted in slightly higher absorbance. A slight increase in absorbance may be due to more pronounced roundness of the particles. 
Although consisting of slightly larger and more agglomerated particles, $4 \mathrm{~g} / \mathrm{L}$ was determined as a more suitable precursor solution due to the well-defined particles, and this sample was analyzed in terms of electrochemical properties and compared with the commercial Pt powder.

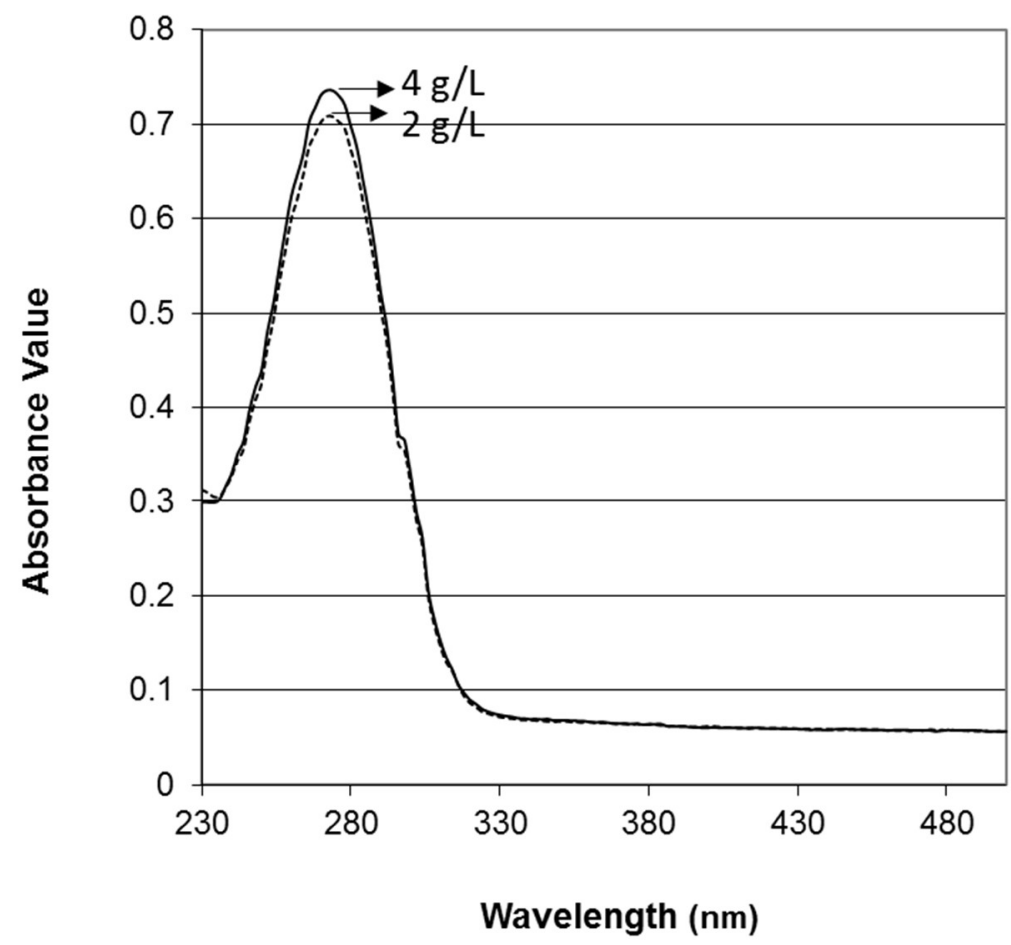

Figure 3. Absorbance vs. wavelength spectra of the synthesized samples.

\subsection{Electrochemical Properties of Obtained Pt Particles}

\subsubsection{Cyclic Voltammetry}

Stable cyclic voltammograms of USP-synthesized Pt (USP-Pt) and Pt black are shown in Figure 4. Both curves had a shape that was characteristic of platinum. Well-resolved Pt oxide formation/reduction peaks were observed for both samples in a wider potential range, with higher CV currents for Pt black. This also holds for hydrogen adsorption/desorption peaks. However, in the double-layer region (around $0.15 \mathrm{~V}$ ), the currents for USP-Pt were smaller, which indicates the formation of slightly smaller Pt particles. Similar findings are valid if $\mathrm{CVs}$ in the narrower potential region are considered. With respect to the wider potential range, hydrogen adsorption/desorption peaks were less pronounced because the surface had not been continuously renewed and reconstructed by reversible oxide formation/reduction. The ratio between CV currents of USP-Pt and Pt black appeared to not be affected by cycling limits. These basic electrochemical properties show that clean $\mathrm{Pt}$ particles of typical characteristics can be synthesized by a simple USP synthesis approach.

\subsubsection{Linear Sweep Voltammetry}

LSV curves for the ORR of USP-Pt and Pt black obtained after CV measurements in shorter and wider potential ranges (Figure 5) represent typical polarization curves for ORR on Pt. The formation of Pt oxide (the case of CV in wider potential range) had a beneficial influence on the ORR activity of both USP-Pt and Pt black samples. Namely, the samples showed better ORR activity after CV measurements in a wider potential range as ORR takes place at more anodic potentials, except in the region of a limiting diffusion current (potentials negative to $0.3 \mathrm{~V}$ ). The reversible oxide formation can cause the growth of $\mathrm{Pt}$ particles and hence reduce the real surface area, which consequently decreases the apparent limiting diffusion current. This effect is more pronounced for USP-Pt due to initially larger Pt particles. 


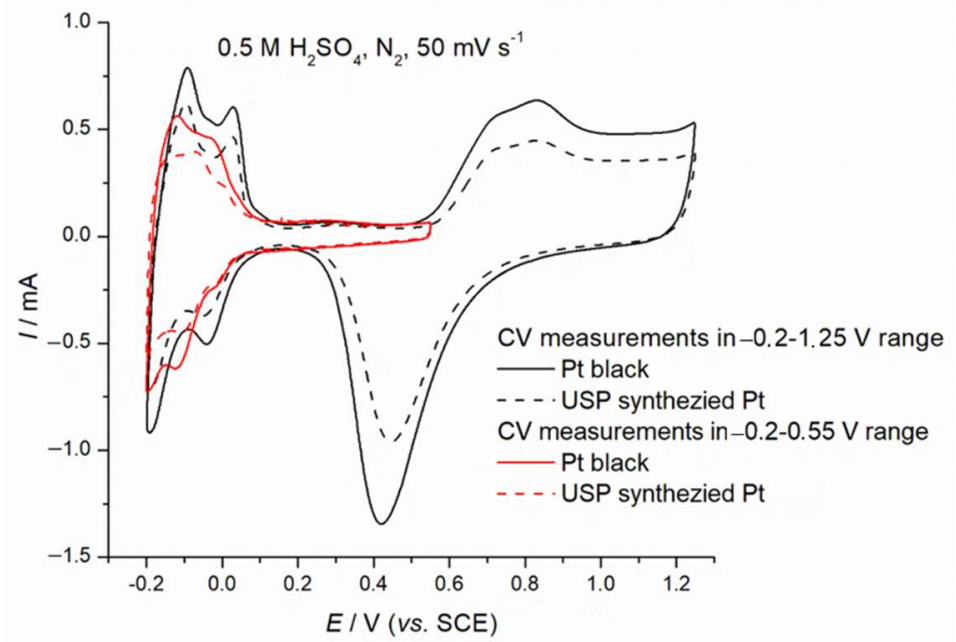

Figure 4. Cyclic voltammograms of USP-Pt and Pt black in shorter $(-0.2-0.55)$ and wider $(-0.2-1.25)$ potential ranges. Electrolyte: de-aerated $0.5 \mathrm{M} \mathrm{H}_{2} \mathrm{SO}_{4}$, sweep rate $50 \mathrm{mV} \mathrm{s}^{-1}$.

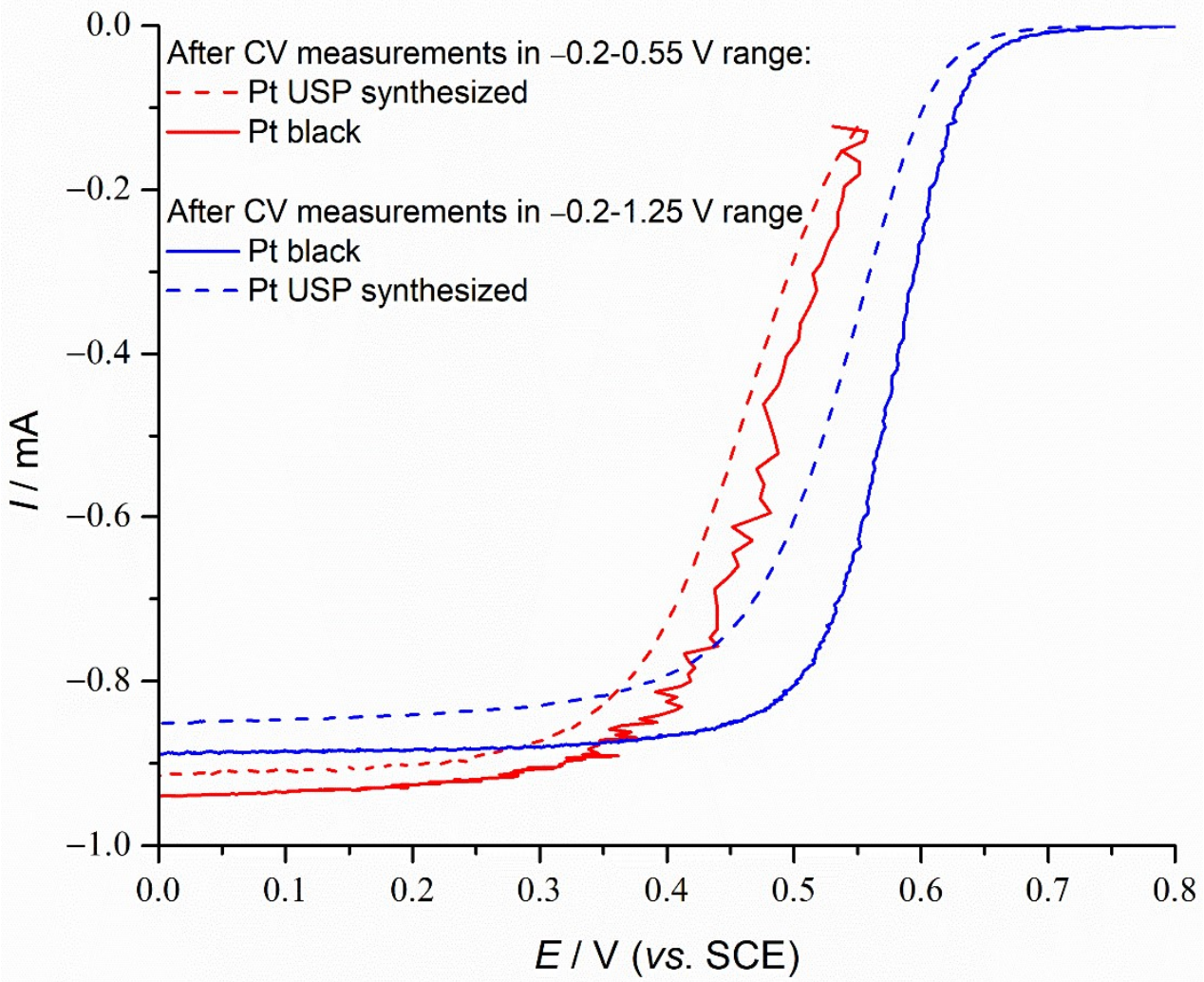

Figure 5. Quasi-steady-state polarization curves of USP-Pt and Pt black obtained after CV measurements in shorter and wider potential ranges. Electrolyte: $0.5 \mathrm{M} \mathrm{H}_{2} \mathrm{SO}_{4}$ purged with $\mathrm{O}_{2}$, room temperature, $1500 \mathrm{rpm}$, sweep rate: $1 \mathrm{mV} / \mathrm{s}$.

ORR required the application of more negative potential for USP-Pt, i.e., apparent currents were higher for Pt black within all the applied potential range. This indicates that Pt black was mainly more active for ORR due to geometric issues, i.e., the Pt black layer on the GC working electrode had a slightly larger real surface area. In addition, the sole low-index $\mathrm{Pt}$ (111) plane was found by electron dispersion (Figure 2) for USP-Pt, which is the least active plane in comparison to the $\mathrm{Pt}(100)$ and $\mathrm{Pt}$ (101) facets [32]. This finding can additionally affect the lower ORR activity of USP-Pt, and can particularly 
cause the registered higher ORR overpotentials of USP-Pt in comparison to Pt black. The limiting current of around $4.6 \mathrm{~mA} \mathrm{~cm}^{-2}$ that was found for USP-Pt is in accordance with the limiting currents ranging 4-6 mA cm${ }^{-2}$ reported for various materials $[4,5,8]$. Namely, platinum-based hybrid materials Pt-Er@PC-900 and Pt-ErPCN-900, i.e., Pt/Er nanoparticles decorated on Cd-MOF derived hierarchical carbon, showed excellent ORR activity with a limiting current of $5.5 \mathrm{~mA} \mathrm{~cm}{ }^{-2}$ while the limiting current of commercial $\mathrm{Pt} / \mathrm{C}$ was $4.7 \mathrm{~mA} \mathrm{~cm}^{-2}$ [8]. A new class of non-platinum electrocatalysts with high stability and activity in ORR was developed by Ibraheem et al. [4,5]. The ORR activity of these new hybrid non-platinum materials was comparable to the activity of commercial $\mathrm{Pt} / \mathrm{C}$ catalysts and even better when in comparison to $\mathrm{IrO}_{2}$. Namely, strongly coupled Fe2NiSe4@FeNC hybrid material showed excellent stability in ORR with a limiting current of around $5.5 \mathrm{~mA} \mathrm{~cm}^{-2}$ [4]. High activity and stability in ORR were preserved when this hybrid material was comprised of $\mathrm{P}$ instead of Se, i.e., a limiting current of $\mathrm{NiFeP}$ supported on three-dimensional, interconnected Fe,N-decorated carbon (NiFeP@3D-FeNC) was around $5.5 \mathrm{~mA} \mathrm{~cm}^{-2}$ [5]. Even unsupported $\mathrm{NiFeP}$ material showed good ORR activity (limiting current of $4.2 \mathrm{~mA} \mathrm{~cm}^{-2}$ ), while unsupported $\mathrm{Fe}_{2} \mathrm{NiSe}_{4}$ exhibited a lower limiting current of $1.5 \mathrm{~mA} \mathrm{~cm}^{-2}$.

\subsubsection{Galvanostatic Electrochemical Impedance Spectroscopy (GEIS)}

The GEIS measurements of the samples were conducted at different steady-state currents depending on whether they were performed after a narrower or wider range of potential had been applied in preceding CV measurements. From Figure 5, the currents analogue to the potential of Pt oxide formation (around 0.6 V from CV in Figure 4) were $-250 \mu \mathrm{A}$ for Pt black and $-150 \mu \mathrm{A}$ for USP-Pt. Therefore, to avoid the formation of $\mathrm{Pt}$ oxide, applied currents in GEIS performed after CV in a shorter potential range were in a range from the diffusion-limited current to -250 , i.e., $-150 \mu \mathrm{A}$. Currents applied in GEIS performed after $\mathrm{CV}$ in a wider potential range (Figure 3) included current values within the ORR region from Figure 5. Given that GEIS results did not differ by much whether they were obtained after $\mathrm{CV}$ in narrower or wider potential regions, only the GEIS results gained after $\mathrm{CV}$ in the wider region are shown in this paper (Figures 6 and 7). This is in accordance with the $\mathrm{CV}$ findings that reversible oxide formation does not really affect the activity of investigated Pt samples.

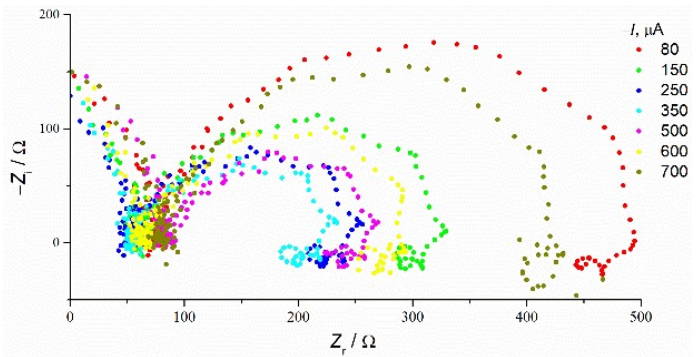

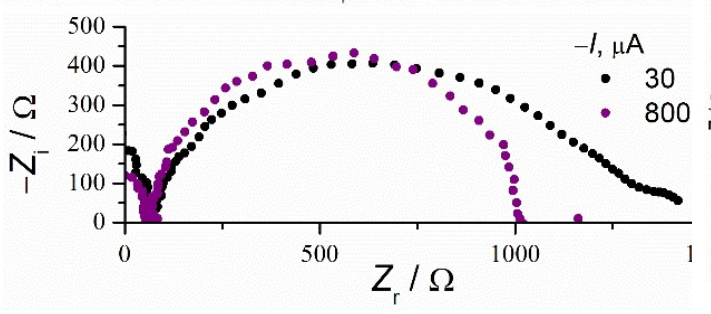

(a)
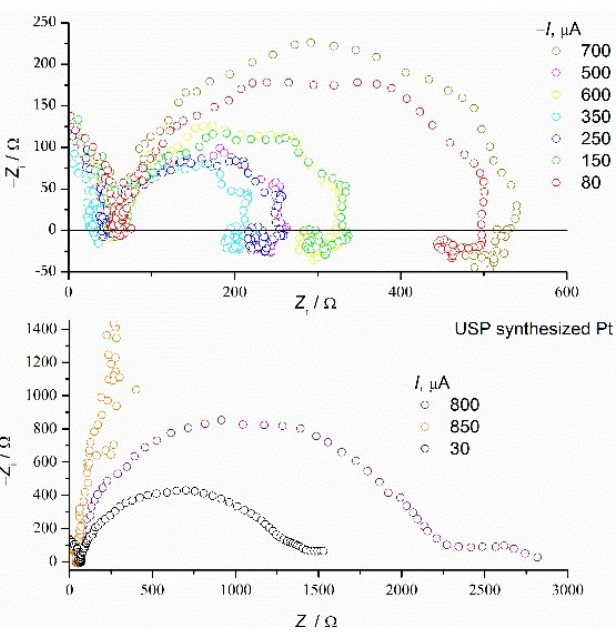

(b)

Figure 6. Nyquist presentation of GEIS results (Pt black (a) and USP-Pt (b)) after CV in a wider $(-0.2-1.25 \mathrm{~V})$ range. Electrolyte: $\mathrm{O}_{2}$ purged $0.5 \mathrm{M} \mathrm{H}_{2} \mathrm{SO}_{4}, 1500 \mathrm{rpm}$. 

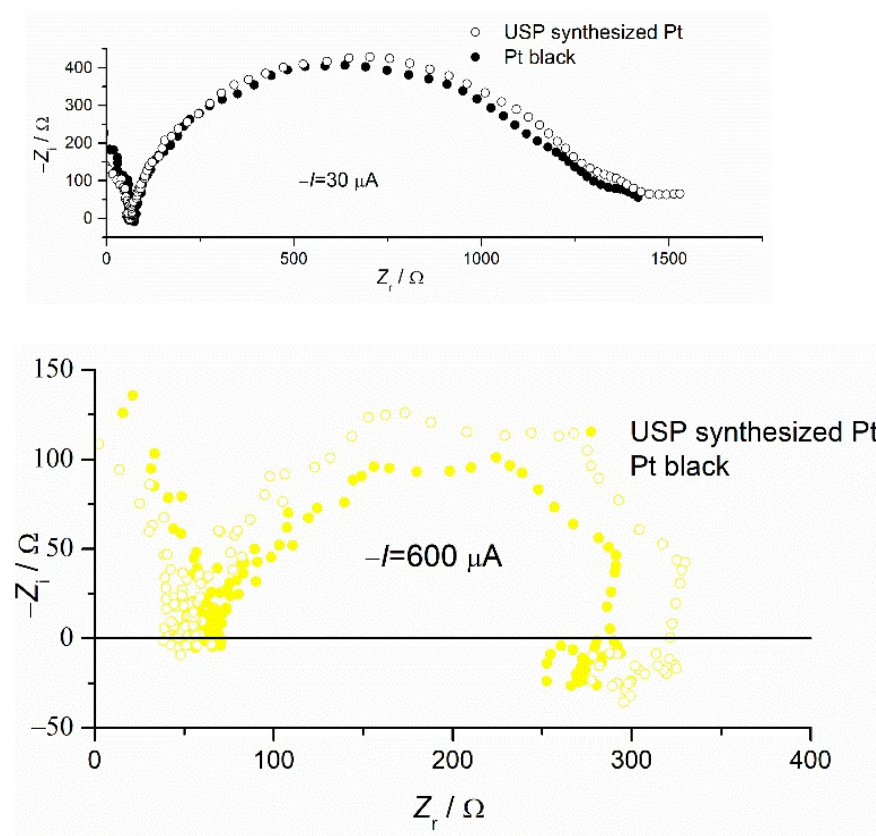
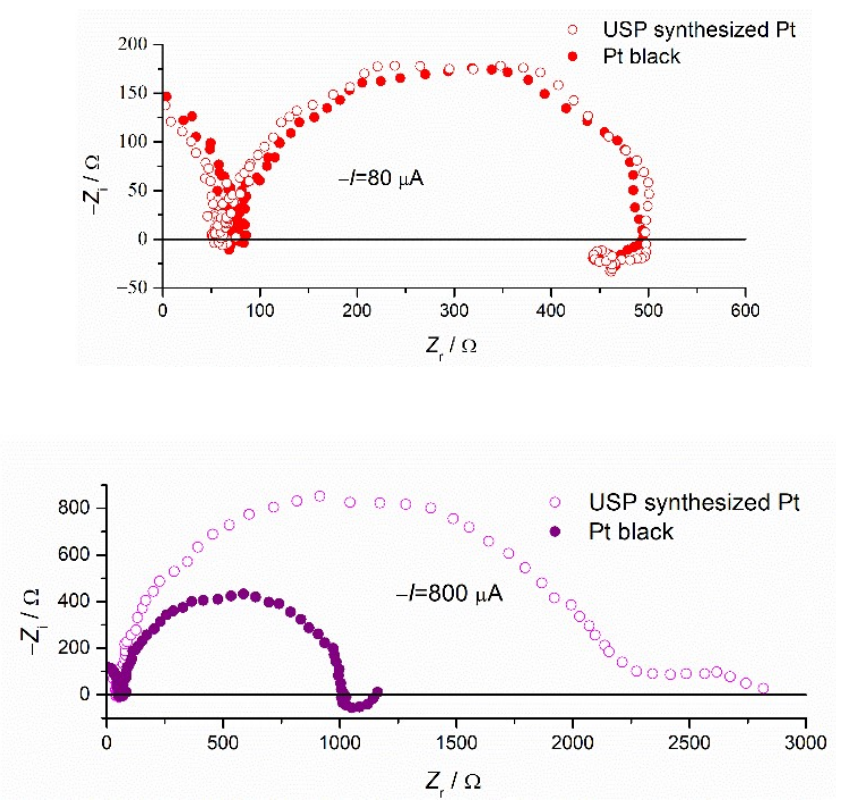

Figure 7. Detailed Nyquist comparison of GEIS results of Pt black and USP-Pt at specific currents. Electrolyte: $\mathrm{O}_{2}$ purged $0.5 \mathrm{M} \mathrm{H}_{2} \mathrm{SO}_{4}, 1500 \mathrm{rpm}$.

A similar trend in ORR activity was observed for both samples (Figure 3). A charge transfer loop is registered as the main GEIS feature in the investigated frequency range at all applied steady-state currents. The increase in currents in the mixed activation/diffusion region (below $-350 \mu \mathrm{A}$ ) induces the decrease in a loop diameter due to the decrease in charge transfer resistance. For the cathodic currents higher than $-350 \mu \mathrm{A}$, the loop diameter increased with the current due to the intensification of the diffusion limitation of ORR. All loops were of similar shape, except for the loop that registered at the lowest current of $-30 \mu \mathrm{A}$, which was clearly followed in the low-frequency region by an additional small loop. For the USP-Pt sample, this small loop appeared better developed and at somewhat higher frequencies with respect to the data for Pt black. This indicates that the associated ORR kinetics issues are sensitive to the structure of the catalyst layer, which appears to be more compact in the case of Pt black due to smaller particles and larger real surface area. This seems to also affect the difference in loop features at the highest applied current of $-800 \mu \mathrm{A}$. The low-frequency loop was uniquely preserved under pronounced diffusion control for USP-Pt. This apparently caused the loop diameter for USP-Pt at $-800 \mu \mathrm{A}$ to be almost three times larger than that for Pt black. However, the loops for USP-Pt and Pt black at other applied currents appeared quite similar in diameter. This difference with respect to polarization measurements (Figure 5), which indicated the higher activity of Pt black, deserves further analysis, according to Figure 7.

Figure 7 presents a comparison of some GEIS results at specific currents, taken from Figure 6 (the values of the currents are shown within).

Although the LSV measurement (Figure 2) showed better ORR activity of the Pt black within the whole current range, GEIS results indicated almost the same activity at lower currents, i.e., up to $-500 \mu \mathrm{A}$ (the loops were of quite similar diameters). However, with the increase in the applied current in GEIS, starting from I $=-600 \mu \mathrm{A}$ (Figure 4), better activity of the Pt black appeared. Finally, at the highest applied current $(-800 \mu \mathrm{A})$, the Pt black activity was doubled in comparison to the USP-Pt activity. It then follows that the differences in activity are strictly connected to the onset of pure diffusion limitations; therefore, they are not connected to the chemical structure of the investigated samples but to the morphology of the electrode layers, as already discussed. 
In order to comment on the differences between polarization and GEIS data, a comparison of ORR activity registered in GEIS and LSV measurements for Pt black and USP-Pt is presented in Figure 8. For this comparison, the square root of the potentials was collected from GEIS data at chosen frequencies (indicated in the figure) from low- and high-frequency regions and plotted against the steady-state GEIS current. Both USP-Pt and Pt black are more active if the sinusoidal perturbation of the current is of higher frequency, and they are even of higher activity, especially in a mixed reaction control, with respect to the quasisteady-state data. This indicates the distribution of the activity throughout the catalyst layer, with more active sites situated in the outer regions because these sites respond to fast current perturbations. The main difference between the two samples is that this distribution of the active sites is more pronounced for Pt black. USP-Pt does not lack activity at lowfrequency perturbations with respect to standard polarization. This means that all active sites would be available during the ORR operation, which is to be expected as being more stable with respect to Pt black. Apparently, these valuable features of USP-Pt in comparison to Pt black are due to a less-compact layer structure caused by larger Pt particles.

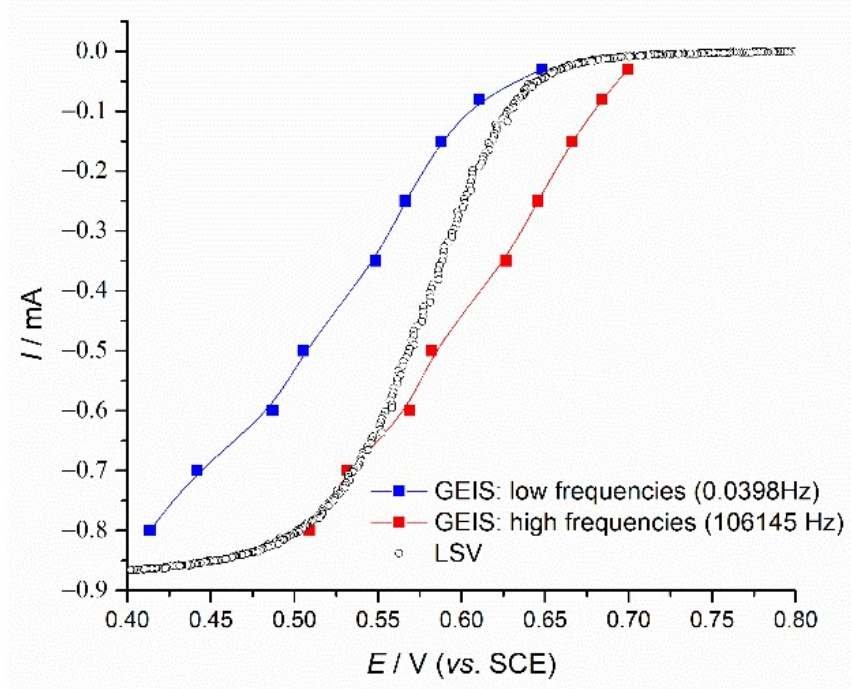

(a)

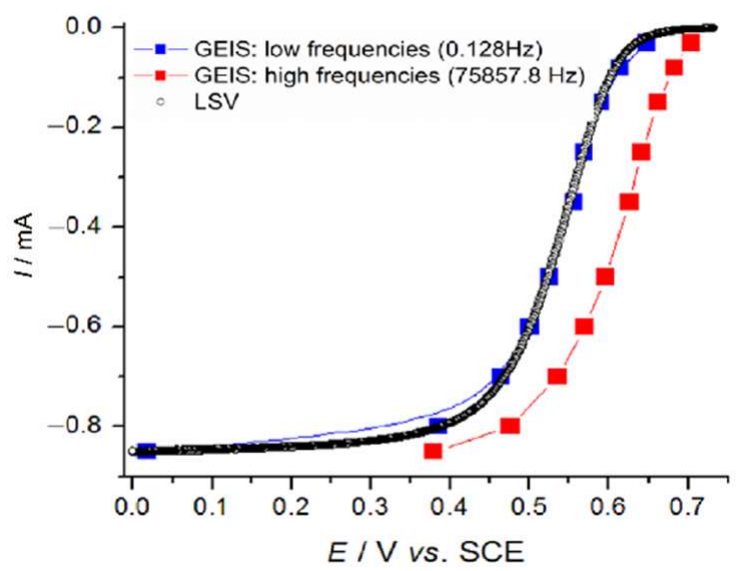

(b)

Figure 8. Comparison of Pt black (a) and USP-Pt (b) ORR activity collected from GEIS and LSV measurements.

\section{Conclusions}

Ultrasonic spray pyrolysis (USP) was used for the synthesis of Pt particles, which started from using $\mathrm{H}_{2} \mathrm{PtCl}_{6} \times 6 \mathrm{H}_{2} \mathrm{O}$ water solution as a precursor without using any synthesis additives to tune structural and morphological properties. The USP synthesis temperature for low residence time was chosen according to thermogravimetric measurements. Results showed that polygonal round-edge and phase-pure Pt nanoparticles with face cubic centered structures were successfully synthesized. The particle size, defined shape, and agglomeration were found to be sensitive to precursor concentration, and higher concentrations were found to be beneficial due to the synthesis of more defined particles.

Electrochemical characterization revealed good electrocatalytic activity of the synthesized material, which was comparable to commercial Pt black. It is found that USP-Pt is of a lower real surface area due to the larger particle size with respect to Pt black. As a consequence, USP-Pt appears less active in quasi-steady-state polarizations in the oxygen reduction reaction (ORR). However, upon dynamic perturbations performed by galvanostatic impedance measurements (GEIS), the difference in ORR activities between the two investigated powdered $\mathrm{Pt}$ was found negligible. Only the diffusion-limited currents were 
found to be higher for Pt black due to the larger real surface area, i.e., the somewhat smaller particles.

The beneficial features of USP-synthesized Pt were found upon the comparison of steady-state and dynamic (GEIS) electrocatalytic data in ORR. USP-Pt is less sensitive to the rate of current perturbations due to larger particles and, consequently, a less-compact catalyst layer. A more defined response of USP-Pt in ORR polarization could be considered as an indication of its higher stability with respect to Pt black.

Author Contributions: Conceptualization, J.S. and B.F.; methodology, V.P. and M.M.; formal analysis, G.A. and M.K.; investigation, G.A. and M.K.; data curation, G.A. and M.K.; writing-original draft preparation, G.A. and M.K.; writing—review and editing, V.P.; supervision, V.P., B.F. and J.S.; project administration, M.M. and S.S. All authors have read and agreed to the published version of the manuscript.

Funding: This work was funded by the Serbian Ministry of Education, Science and Technological Development Grant No. 451-03-9/2021-14/200026.

Conflicts of Interest: The authors declare no conflict of interest.

\section{References}

1. Pei, Y.; Hu, M.; Xia, Y.; Huang, W.; Li, Z.; Chen, S. Electrochemical preparation of Pt nanoparticles modified nanoporous gold electrode with highly rough surface for efficient determination of hydrazine. Sens. Actuators B Chem. 2020, 304, 127416. [CrossRef]

2. Mello, R.L.S. Preparation and electrochemical characterization of Pt nanoparticles dispersed on niobium oxide. Eclet. Quím. 2003, 28, 69-76. [CrossRef]

3. Yasin, G.; Ibrahim, S.; Ibraheem, S.; Ali, S.; Iqbal, R.; Kumar, A.; Tabish, M.; Slimani, Y.; Nguyen, T.A.; Xu, H.; et al. Defective/graphitic synergy in a heteroatom-interlinked-triggered metal-free electrocatalyst for high-performance rechargeable zinc-air batteries. J. Mater. Chem. A 2021, 9, 18222. [CrossRef]

4. Ibraheem, S.; Chen, S.; Peng, L.; Li, J.; Li, L.; Liao, Q.; Shao, M.; Wei, Z. Strongly coupled iron selenides-nitrogen-bond as an electronic transport bridge for enhanced synergistic oxygen electrocatalysis in rechargeable zinc-O2 batteries. Appl. Catal. B Environ. 2020, 265, 118569. [CrossRef]

5. Ibraheem, S.; Chen, S.; Li, J.; Li, W.; Gao, X.; Wang, Q.; Wei, Z. Three-dimensional Fe,N-decorated carbon-supported NiFeP nanoparticles as an efficient bifunctional catalyst for rechargeable zinc-O2 batteries. ACS Appl. Mater. Inter. 2019, 11, 699-705. [CrossRef]

6. Olabi, A.G.; Sayed, E.T.; Wilberforce, T.; Jamal, A.; Alami, A.H.; Elsaid, K.; Rahman, S.M.A.; Shah, S.K.; Abdelkareem, M.A. Metal-Air Batteries-A Review. Energies 2021, 14, 7373. [CrossRef]

7. Ibraheem, S.; Yasin, G.; Kumar, A.; Mushtaq, M.A.; Ibrahim, S.; Iqbal, R.; Tabish, M.; Ali, S.; Saad, A. Iron-cation-coordinated cobalt-bridged-selenides nanorods for highly efficient photo/electrochemical water splitting. Appl. Catal. B Environ. 2022, 304, 120987. [CrossRef]

8. Yasin, G.; Ibraheem, S.; Ali, S.; Arif, M.; Ibrahim, S.; Iqbal, R.; Kumar, A.; Tabish, M.; Mushtaq, M.A.; Saad, A.; et al. Defectsengineered tailoring of tri-doped interlinked metal-free bifunctional catalyst with lower gibbs free energy of OER/HER intermediates for overall water splitting. Mater. Today Chem. 2022, 23, 100634. [CrossRef]

9. Nadeem, M.; Yasin, G.; Arif, M.; Tabassum, H.; Bhatti, M.H.; Mehmood, M.; Yunus, U.; Iqbal, R.; Nguyen, T.A.; Slimani, Y.; et al. Highly active sites of $\mathrm{Pt} / \mathrm{Er}$ dispersed $\mathrm{N}$-doped hierarchical porous carbon for trifunctional electrocatalyst. Chem. Eng. J. 2021, 409, 128205. [CrossRef]

10. Motsoeneng, R.G.; Modibedi, R.M.; Mathe, M.K.; Khotseng, L.E.; Ozoemena, K.I. The synthesis of PdPt/carbon paper via surface limited redox replacement reactions for oxygen reduction reaction. Int. J. Hydrog. 2015, 40, 16734-16744. [CrossRef]

11. Vidal-Iglesias, F.J.; Ara, R.M.; Solla-Gullo, J.; Herrero, E.; Feliu, J.M. Electrochemical Characterization of Shape-Controlled Pt Nanoparticles in Different Supporting Electrolytes. ACS Catal. 2012, 2, 901-910. [CrossRef]

12. Kim, J.W.; Lim, B.; Jang, H.-S.; Hwang, S.J.; Yoo, S.J.; Ha, J.S.; Cho, E.A.; Lim, T.-H.; Nam, S.W.; Kim, S.-K. Size-controlled synthesis of Pt nanoparticles and their electrochemical activities toward oxygen reduction. Int. J. Hydrog. Energy 2010, 36, 706-712. [CrossRef]

13. Stepanov, A.L.; Golubev, A.N.; Nikitin, S.I.; Osin, Y.N. A review on the fabrication and properties of platinum nanoparticles. Rev. Adv. Mater. Sci. 2014, 38, 160-175.

14. Tao, A.R.; Habas, S.; Yang, P. Shape control of colloidal metal nanocrystals. Small 2008, 4, 310-325. [CrossRef]

15. Lau, M.; Gökce, B.; Marzun, G.; Rehbock, C.; Barcikowski, S. Rapid nanointegration with laser-generated nanoparticles. Lasers Manuf. Conf. 2015, 109, 1-7.

16. Alkan, G.; Diaz, F.; Matula, G.; Stopic, S.; Friedrich, B. Scaling up of nanopowder collection in the process of ultrasonic spray pyrolysis. World Metall Erzmetall. 2017, 70, 97-101. 
17. Alkan, G.; Rudolf, R.; Bogovic, J.; Jenko, D.; Friedrich, B. Structure and Formation Model of Ag/TiO2 and Au/TiO2 Nanoparticles Synthesized through Ultrasonic Spray Pyrolysis. Metals 2017, 7, 389. [CrossRef]

18. Messing, G.L.; Zhang, S.C.; Jayanthi, G.V. Ceramic Powder Synthesis by Spray Pyrolysis. J. Am. Ceram. Soc. 1993, 76, 2707-2726. [CrossRef]

19. Gurav, A.; Kodas, T.; Pluym, T.; Xiong, Y. Aerosol processing of materials. Aerosol Sci. Technol. 1993, 19, 411-452. [CrossRef]

20. Jung, C.H.; Yun, J.; Qadir, K.; Naik, B.; Yun, J.Y.; Park, J.Y. Catalytic activity of Pt/SiO2 nanocatalysts synthesized via ultrasonic spray pyrolysis process under CO oxidation. Appl. Catal. B Environ. 2014, 154-155, 171-176. [CrossRef]

21. Jung, C.H.; Yun, J.; Qadir, K.; Park, D.; Yun, J.Y.; Park, J.Y. Pt/oxide nanocatalysts synthesized via the ultrasonic spray pyrolysis process: Engineering metal-oxide interfaces for enhanced catalytic activity. Res. Chem. Intermed. 2016, 42, 211-222. [CrossRef]

22. Muñoz-Fernandez, L.; Alkan, G.; Milošević, O.; Rabanal, M.E.; Friedrich, B. Synthesis and characterisation of spherical coreshell Ag/ZnO nanocomposites using single and two-steps ultrasonic spray pyrolysis (USP). Catal. Today 2019, 321-322, 26-33. [CrossRef]

23. Rowston, W.B.; Ottaway, J.M. Determination of noble metals by carbon furnace atomic-absorption spectrometry. Part 1 . Atom formation processes. Analyst 1979, 104, 645-659. [CrossRef]

24. Košević, M.; Zarić, M.; Stopić, S.; Stevanovic, J.; Weirich, T.; Friedrich, B.; Panic, V. Structural and Electrochemical Properties of Nesting and Core/Shell Pt/TiO2 Spherical Particles Synthesized by Ultrasonic Spray Pyrolysis. Metals 2020, 10, 11. [CrossRef]

25. Schweizer, A.E.; Kerr, G.T. Thermal Decomposition of Hexachloroplatinic Acid. Inorg. Chem. 1978, 17, 2326-2327. [CrossRef]

26. Alkan, G.; Rudolf, R.; Emil, E.; Jenko, D.; Friedrich, B.; Gurmen, S. Tuning the Morphology of ZnO Nanostructures with the Ultrasonic Spray Pyrolysis Process. Metals 2018, 8, 569.

27. Gharibshahi, E.; Saion, E. Influence of dose on particle size and optical properties of colloidal platinum nanoparticles. Int. J. Mol. Sci. 2012, 13, 14723-14741. [CrossRef]

28. Nguyen, T.B.; Nguyen, T.D.; Nguyen, Q.D.; Nguyen, T.T. Preparation of platinum nanoparticles in liquids by laser ablation method. Adv. Nat. Sci. Nanosci. Nanotechnol. 2014, 5, 035011. [CrossRef]

29. Du, C.; Sun, Y.; Shen, T.; Yin, G.; Zhang, J. 7 Applications of RDE and RRDE Methods in Oxygen Reduction Reaction. In Rotating Electrode Methods and Oxygen Reduction Electrocatalysts, 1st ed.; Xing, W., Yin, G., Zhang, J., Eds.; Elsevier: Amsterdam, The Netherlands, 2014; pp. 231-277.

30. Zorko, M.; Martins, P.F.B.D.; Connell, J.G.; Lopes, P.P.; Markovic, N.M.; Stamenkovic, V.R.; Strmcnik, D. Improved Rate for the Oxygen Reduction Reaction in a Sulfuric Acid Electrolyte using a Pt(111) Surface Modified with Melamine. ACS Appl. Mater. Interfaces 2021, 13, 3369-3376. [CrossRef]

31. Devivaraprasad, R.; Ramesh, R.; Naresh, N.; Kar, T.; Singh, R.K.; Neergat, M. Oxygen reduction reaction and peroxide generation on shape-controlled and polycrystalline platinum nanoparticles in acidic and alkaline electrolytes. Langmuir 2014, 30, 8995-9006. [CrossRef]

32. Grgur, B.; Marković, N.M.; Ross, P.N. Temperature dependent oxygen electrochemistry on platinum low index single crystal surfaces in acid solutions. Can. J. Chem. 1997, 75, 1465-1471. [CrossRef] 